\title{
Asset Growth and Future Stock Returns: Insight from International Equity Markets
}

\author{
Muhammad Emdadul Haque ${ }^{1}$ \\ ${ }^{1}$ Lecturer in Business, London School of Science and Technology, London, England \\ Correspondence: Dr. Muhammad Emdadul Haque, Lecturer in Business, London School of Science and \\ Technology, London, England.
}

Received: September 1, 2021

Accepted: September 26, 2021

Online Published: October 7, 2021

doi:10.5539/ibr.v14n11p1

URL: https://doi.org/10.5539/ibr.v14n11p1

\begin{abstract}
The main purpose of this research is to examine the cross-sectional connection between asset growth and stock returns in the international equity market during 2016-2020. Firms in international equity markets, subsequently experience lower stock returns with higher asset growth rates, consistent with the United States evidence. If capital markets are well-developed stocks efficiently priced then the negative AG effect on returns is likely to be stronger, but different to country characteristics representing accounting quality, investor protection, and limits to arbitrage. The research is to examine the cross-sectional connection between the asset growth and stock return in the international equity market is likely due to optimal investment effect than due to market timing, overinvestment, or other forms of mispricing. The evidence suggests that the cross-sectional association between the AG effect and stock return is more likely due to an optimal investment effect than due to overinvestment, mispricing or market timing. The findings of the research support Copper et al (2008) however, the weakening of the accounting quality decreases the AG effect magnitude which contradicts the mispricing-based arguments.
\end{abstract}

Keywords: asset growth, stock return, arbitrage, mispricing, investor, optimal investment, return on equity, equal weighted measures, value weighted measures, Cross country analysis

\section{Introduction}

It has been recognised that firms experiencing rapid growth by making capital investments and raising external financing subsequently have low stock returns, while firms experiencing contraction via debt retirement, share repurchase, and divestiture enjoy high future returns (Cooper et al., 2008). The researchers also summarise the synergistic effect of financing activities and firms' investment by implementing a straightforward measure of the total asset. In their research, they report that during the period from 1968 to 2003 in the United States, a value weighted portfolio of stocks in the bottom asset growth decile overperforms by $13 \%$ than the portfolio of stocks in the top decile per year, and by Standard asset pricing model cannot explain cross-sectional return difference. In the current finance literature, one of the most actively disputed issues is whether the negative outcome of financing and investment on stock returns, as highlighted by the AG effect can be shown as a rational asset pricing result or evidence of market inefficiency. Quite a lot of mispricing based statements have been suggested from the behavioural camp (Watanabe et al.2013). In addition, Cooper et al. (2008) added that the AG effect is weaker in times of increased corporate oversights, which is consistent with the result of AG effect arises in part from managerial overinvestment and investor under-appreciation of managerial empire building. A significant bias identifies in the growing market's capitalisation of corporate asset disinvestment or investment. Moreover, Liu et al (2009), and Cochrane (1996) added that, firms with low discount rates are likely making large investments. In addition, Li et al. (2009) also added higher investments are connected with lower expected returns. If discounted cash flow is equal to the value of any investment project that it generates, then businesses will invest when they expect lower discount rates (risks) or higher future cash flows and this explanation is based on Tobin's (1969) and Yoshikawa's (1980) $q$-theory. Considering this theory, we expect that, asset growth should be negatively connected with future stock returns, as long as investment levels are negatively associated with potential discount rates to some extent. Mispricing-based interpretations are favoured by Li and Zhang (2010) under the $q$ theory model of the return on investment, corporate investment connection should be stronger among firms facing elevated financing frictions and investment. Practically, Li and Zhang (2010) find little evidence for the prediction using different investment frictions, proxies for investment, and costs of arbitrage. Lam and Wei 
(2011) using the most complete set of arbitrage costs show that the limit to arbitrage cost effect and the investment friction effect is supported by the comparable amount of evidence.

The research used last 5 years data collected from Bloomberg terminal; Evidence showed an important effect of asset growth in the international equity markets. Outside the United States, the research pool stocks across 11 countries from the different regions; emerging and developed and arrange into equal weighted decile portfolios considering the rates of annual asset growth (AG), subsequent year, bottom decile do $9.07 \%$ better than the top decile. Considering Except U.S., all other counties the research found, the return spreads between the top and bottom AG portfolios formed ranges from $-8.24 \%$ to $7.38 \%$ within each country. Interestingly, it can be seen that half of the return spreads are positive when we included the United States. Such divergence of cross-country provides a reason for analysing different hypotheses on the cause of the effect of asset growth.

The cross-sectional examinations around two different facts connect the AG effect to different country characteristics in conflict ways. Firstly, it is expected that the asset growth to be stronger in countries if it is due to mispricing where mispricing is hard to arbitrage. In addition, if management empire-building, accounting manipulation or capital structure market timing are following the anomaly asset growth, this outcome to be stronger corporate governance with weaker in countries, less room for accounting manipulation and better investor protection. Secondly, if optimal corporate investment decision drives the AG effect would be stronger in international markets where efficiently stocks are priced (Watanabe et al. 2013). Titman (2011) shows that, within the developed markets, financing externally is a significant determining factor of the magnitude of the effect of asset growth. Compared to their research, this research comprises a complete set of country features and includes the emerging and the developed markets.

\subsection{Research Objectives}

This study examines the effect of asset growth in international markets. The first objective is to investigate whether the negative connection between asset growth and future stock returns exists in financial markets outside the United States. Because the prior researcher Cooper et al. (2008) shows the annual asset growth rate of a firm emerges as a substantially and economically predictor of the cross-section of United States stock returns and, a positive response would improve the concern that due to coincidental or data snooping the experiential pattern documented in U.S. Second to examine the possible economic cause of the asset growth and effect we use the international data. The research approach builds upon Lam and Wei (2011) and Li and Zhang (2010), but the large dispersion of country characteristics and the large difference in the asset growth effect allow the research to perform a new set of statistical tests for examining theories.

\subsection{Research Questions}

The research aimed to examine the cross-sectional connection between the growth of assets and future stock returns in the international equity market during 2016-2020. The research problem comprises three sub problems to achieve the objectives of the study.

\subsubsection{Sub Problem 1}

To examine is on the relation between the AG effect and market efficiency. Market efficiency role is the focal point of the first hypothesis. The effect of optimal investment stands on either the effect of real options or the $q$ theory.

\subsubsection{Sub Problem 2}

To examine is on the effect of limits to arbitrage. The AG effect should be stronger if it is due to mispricing whereas mispricing is hard to arbitrage away.

\subsubsection{Sub Problem 3}

To examine the directly related plausible causes of the asset growth effect. It assumes that the magnitude of the asset growth effect to be connected to the accounting information disclosed quality, protection of outside investors, and earnings manipulation practice.

\section{Models}

The market efficiency role in describing the AG effect under a $q$-theory model of corporate investment. This research paper will be performed by the latest models and methods followed by Chen et al. (2011) and Watanabe (2013). In addition, A complete panel model of the effect of asset growth is considered by the within effect regressions in the following form: $Y_{i, t}=\beta_{0}+\beta_{1} X_{i, t}+u_{i}+e_{i, t}$. 


\section{Discussion}

The main principle of this research is to examine the cross-sectional connection between the growth of assets and future stock returns in the international equity market. The research problem comprises three sub problems to achieve the objectives of the study. Firstly, the research examines the relationship between the AG effect and market efficiency. Secondly, the research problem is to scrutinise the effect of limits on arbitrage. Secondly, the research will investigate the directly related plausible causes of the AG effect. The literature review addresses the theoretical framework that governs optimal investment effects, mispricing-based explanations, asset growth and stock return, and a review of the past empirical literature. The discussion started with different explanations proposed in the literature on the connection between investment and stock returns. After that, tried to outline hypotheses based on these explanations and international data will be used to test the hypotheses.

\subsection{Optimal Investment Effects}

The optimal investment explanations of asset growth and stock returns connection are based on either the effect of real options or a particular $q$-theory. The model is adopted from Li and Zhang (2010) for illustration purpose to underline the two effects of investment which is stimulated by the $q$ theory. Two effects are considered as 1 and 0 . During period 0 , firm ' $i$ ' makes investment $I_{i 0}$ investment adjustment cost. Again, considering $\delta$ is the rate of capital depreciation $K_{i t}$, the firm's capital develops as $K_{i 1}=I_{i 0}+(1-\delta) \mathrm{K}_{\mathrm{io}}$. The convex adjustment of investment cost is quadratic in $I_{i 0}: \mathrm{C}\left(\mathrm{I}_{\mathrm{i} 0}, \mathrm{~K}_{\mathrm{io}}\right)=\frac{\lambda_{\mathrm{i}}}{2}\left(\frac{I_{i o}}{K_{i o}}\right)^{2} K_{i o}$. The peak of investment friction where value of $\lambda_{\mathrm{i}}$ higher then investment should have a stronger negative connection with the expected returns among firms will meet with higher investment frictions. Where marginal productivity of capital is $\Pi$ then the operating profit of firm's is $\Pi \mathrm{K}_{i t}(t=1$ and 0$)$. Considering free cash flow of the firms for period 1 is $\Pi \mathrm{K}_{\mathrm{i} 1}+(1-\delta) \mathrm{K}_{\mathrm{i} 1}$ and for period 0 is $K_{i o}-I_{i o}-\frac{\lambda_{i}}{2}\left(\frac{I_{i o}}{K_{i o}}\right)^{2} K_{i o}$. (Assuming no capital investment beyond period 0 ) followed by (Watanabe et al. 2013). Now, according to $\mathrm{Li}$ and Zhang (2010): PV of the free cash flows is maximized which is the prime objective of any firm.

$$
\max _{i o} \Pi K_{i o}-I_{i o}-\frac{\lambda_{i}}{2}\left(\frac{I_{i o}}{K_{i o}}\right)^{2} K_{i o}+\frac{1}{\mathrm{R}_{\mathrm{i}}}\left[\Pi \mathrm{K}_{\mathrm{i} 1} 1+(1-\delta) \mathrm{K}_{\mathrm{i} 1}\right]
$$

In addition, $\mathrm{Li}$ and Zhang (2010) stated that where $R_{i}$ is the expected return or the discount rate. The firm's optimal investment's first-order condition:

$$
R_{i}=\frac{\Pi+1-\delta}{1+\lambda_{i} \frac{I_{i o}}{K_{i o}}} \quad \cdots
$$

Here, is the cost of capital denotes as $R_{i}$, whereas, right side of the equation is marginal investment return which divides the benefit of marginal investment. It implies that, if the marginal return on investment is equal to the cost of capital then the optimal level of investment will be reached. According to Cochrane (1996) and Cochran (2011) considered two investment effects on future returns; the first effect represents the "discount rate channel," depreciation rate $(\delta)$ and holding profitability $(\Pi)$. Equation (2) explained the optimality state. The "cash flow channel" is the second effect proposed by Lyandres et al. (2008) and Li et al. (2009). From equation (2) the right-hand side is the investment return denotes a decrease in investment if $\Pi$ decreases with investment. Thus, the expected return, the left-hand side of the equation must also be decreasing in investment. Both the cash flow channel and the discount rate channel in the context of the accruals anomaly discussed by Wu, et al. (2010).

The AG effect explanation also offers by the real options literature which assumes that the asset in place is safer than real options. The real options are exercised when firms make investments into less risky places. Thus, consider the lower expected returns due to lower risk, firms making large investments.

\subsection{Mispricing-Based Explanations}

Four types of mispricing-based explanations are proposed by the literature on the negative relation between investment and expected returns whereas, the first explanation is based on overinvestment. On behalf of the 
firms when corporate managers make investment decisions, they are subject to agency problems. Managers may invest in a project with a negative NPV due to empire-building tendency which reduces firms' value. In addition, Titman et al. (2004) show this observation due to investor misreaction.

In finance decisions, market timing behaviour is the second explanation (Baker and Wurgler, 2002). This explanation shows if firms have information about the value of their own when overpriced then they may raise equity financing but if undervalued then they will buy back shares. When investors value stocks and do not completely consider opportunistic corporate behaviour into account, this connects corporate financing negatively with stock returns.

Corporate earnings management is the third potential explanation (Teoh et al., 1998a and Teoh et al., 1998b). Before engaging in acquisitions or raising external financing. To achieve financing terms or favourable market valuation firms may manipulate reported corporate earnings upward. Hence, even though investment or financing has no fundamental effect on returns, a contemporaneous connection between overvaluation and asset growth may be created by earnings management as a result a negative association between the growth of assets and stock returns will be observed.

Investors' extrapolation bias is the final potential explanation. According to Lakonishok et al. (1994), when investors value stocks, they may overvalue from firms' past growth and subsequent low returns. However, Cooper et al. (2008) pointed idea implies the effect of asset growth. When investors value stocks they misreact to publicly available information, above mispricing-based explanations based on the assumption.

\subsection{Asset Growth and Stock Return}

To quantify the magnitude of the growth of the asset (AG), two measures are used within each country. One is the return spread of a sorted portfolio. At the end of June of year $t$, the researcher sort stocks in each country into a portfolio based on AG observed at that time point. To ensure enough stocks in each portfolio following procedures are used. In a given year, the research form tercile portfolios, quintiles and deciles for the number of stocks are between 4 and 7, between 7 and 11 and more than 11 stocks respectively. These portfolios we refer to the Asset Growth bucket portfolios following by (Watanabe et al. 2013). In similar research, Watanabe et al. (2013) sort stocks into tercile/quintiles/ deciles/ buckets if the number of stocks is greater than 30/50/100 respectively. We use a smaller number of stocks. Yearly stocks returns are obtained from Bloomberg Terminal and can compute yearly holding period returns for each stock from July of year $t$ to June of year $t+1$. To get the annual return spread, from the bottom-bucket minus top-bucket AG portfolio returns is represented as SPREAD.

From univariate predictive regressions, the second type of measure of the effect of the asset growth was derived. The researcher regresses annual stock returns within each country from July of year $t$ to June of year $t+1$ cross-sectionally on asset growth examined June of year $t$. SLOPE is the per unit asset growth effect, one time negative SLOPE value is the regression coefficient so that, a positive SLOPE value shows a negative association between asset growth and future stock returns (Watanabe et al. 2013). The researchers Watanabe et al. (2013) also measure SPREAD and SLOPE to make sure the robustness of inference based on both value-weighting and equal weighting will denominate in local currency and local currency. The weights for the value weighted SPREAD are based on individual stocks of the market capitalisations. The weighted-least-squares (WIS) regressions are used to obtain the value weighted SLOPE followed by (Watanabe et al. 2013).

\section{Hypothesis}

A quite different set of descriptions on the effect of asset growth have been proposed by existing studies. To empirically validate every feature of this explanation is not our objective of this study. To a certain extent, we try to distil a few forecasts that can be examined at the country level applying the international data.

The research focuses on the role of market efficiency which is related to the first hypothesis. The optical investment effects are based on either the real options model or the $q$ theory. As already explained the real options are exercised when firms make investments into less risky places. Thus, consider the trend of lower expected returns due to lower risk, firms making large investments. That is, accurate stocks pricing reflects optimal corporate investments effect on the amount of risk involved and the expected cash flows. The corporate investments effect on the stock estimation may ignore if the stocks prices do not correctly reflect the corporate fundamental information. On the other hand, mispricing should be less rampant, when stocks prices accurately reflect firms' fundamental information. Therefore, in more efficient financial markets the magnitude should be weaker if the effect of asset growth is due to various forms of mispricing.

From the mispricing perspective, the second hypothesis was introduced. If the effect of asset growth is due to 
mispricing, then the asset growth effect should be weaker when it is easier for shareholders to do business on systematic patterns of mispricing. Following Li and Zhang (2010), and Lam and Wei (2011), the research looks into a worldwide version of the limit to arbitrage hypothesis. The benefit of examining international data, it has a large difference in trading frictions across markets. For example, some markets in a small sample have precise limitations on equity short-selling.

The last hypothesis is based on the mispricing perspective. However, the third hypothesis is different findings from the second which directly focuses on the mispricing of the growth asset with the exclusion of the effect of extrapolation bias, managers agency problem relies on the other three mispricings based explanation is the overinvestment hypothesis, the earnings management hypothesis, and the market timing hypothesis. Thus, it anticipates the magnitude of the effect of asset growth to be connected to the protection of outside investors, corporate governance, the rampancy of the earnings manipulation practice, and the quality of disclosed accounting information.

\section{Motivation of the Study}

It is expected asset growth to be stronger in countries if it is due to mispricing which is difficult to arbitrage. On the other hand, if optimal corporate investment decisions drive the AG effect would be stronger in markets if stocks are priced efficiently. Based on this idea, three hypotheses are formulated and investigate empirically. To examine different explanations for the effect of asset growth the research used cross-country analysis.

\section{Research Methodology}

To identify market efficiency, we use the group of country characteristics proxies. From H1 -a positive relationship between the AG effect and market efficiency suggests by the explanation of optimal investment, while the explanation of mispricing suggests the opposite.

Where stocks are more efficiently priced, the optimal investment explanation proposes a stronger AG effect among countries. On the other hand, mispricing suggests the opposite. For financial market efficiency, three-country characteristics variables (country level proxies) would be considered. The $1^{\text {st }}$ proxy is stock return synchronicity (R2) (Morck et al., 2000) which is connected negatively to the amount of specific information of firms included in individual stock prices. Weekly individual stock returns will be regressed on the two lags and two leads of the weekly market returns plus contemporary weekly market returns, and after that, from the firm-level regression separately from each country we will take the average $R^{2}$. This is how we will calculate R2

The $2^{\text {nd }}$ is the FERC, developed in the accounting literature which contains the extent to which stock price reflects the information of the future corporate earnings (Collins et al.1994). The FERC of the stock-level calculates as the future earning coefficients change then add all these three, that will get by regressing the current year's earnings change of the annual stock returns of the firm. The research will find the country level FERC across all firms in the country by the mean of the FERC.

The $3^{\text {rd }}$ market efficiency proxy is an indicator for developed markets, DEV will be used which is granted by the International Finance Corporation. Whereas it is generally believed that an emerging market is less informationally efficient than developed stock (LaPorta et al., 1997).

To measure the importance of the AG Effect in each country, the research will take into account both the return Spread (SPREAD) between the slope coefficient (SLOPE) and the extreme AG portfolios from the stock returns cross-sectional regression. It will be examined SPREAD as well as both and value weighted and equal weighted versions of SLOPE. Based on these measures followed by (Watanabe et al, 2013) we try to find the AG effect is stronger in countries where higher FERC and lower $R^{2}$, in economies and developed markets were more significant role played by stock markets. It can be predicted that there would be a stronger return-predictive power of AG where stock markets are more efficient stock markets. This result will be consistent with the optimal investment explanation, but such evidence definitely will contradict the mispricing explanation.

After examining four potential proxies for financial market efficiency as well as SLOPE and SPREAD for measuring the significance of the AG effect, we will finally investigate a financial market efficiency using under a specific q-theory. Recent studies by Chen et al. (2011) and Watanabe et al. (2013) underline a conditional investment-return connection on a firm's profitability. Therefore, we will follow a construct alternative method used to test the similar research sub problem by Watanabe et al. (2013) to examine the AG effect of country-level performing regressions and portfolio sorts that control ROE for firm-level. We will try to find whether these alternative measures or the using the four proxies come up with a similar predictive result. 
The effect of limits to arbitrage will be investigated in this sub-section. Considering alternative hypothesis 2 we will review the idea of Li and Zhang (2010), Lam and Wei (2011) and Li et al. (2011) expect that if mispricing is difficult to arbitrage away then there should be a strong AG effect. Whereas their idea is consistent with the effect of AG in the United States the above AG effect will be applied at the country level which depends on trading friction's three measures are the average stock liquidity: dollar trading volume (DVOL), the average idiosyncratic return volatility (IRISK) and short-sale permission indicator (SHORT). Here, we will examine only SHORT to check if the result remains the same due to complexity and time issue related to collecting data. Prior studies sharply contrast with the United States evidence. We will compare with the existing studies to investigate if there is a relatively weak cross-country association between the AG effect and the limits to arbitrage proxies. Only IRISK demonstrates some power of marginal explanatory, whereas it is expected SHORT always have an important effect. After reviewing the prior literature, we finally expect that the United States evidence supporting the explanation of costly arbitrage cannot be produced in the AG effect for the cross-country difference.

In the third hypothesis, we will examine the directly related plausible causes of the AG effect under the mispricing explanation. Several sources of mispricing, such as firms' tendency of overinvestment, earnings management practices, and opportunistic financing behaviour connected with asset growth which is identified in existing studies. Considering these explanations, it seems there should be a stronger association on the AG effect on stock return among countries with lower accounting quality and less investor protection. After classifying countries, in the second step, we will implement the idea of LaPorta et al. (1998) based on a variety of characteristics of legal protection to secure lenders in a country that measures the index of creditor rights (CR). Now, in the third part, we will consider an index of anti-director rights (AD) which is created by (Djankov, 2007) computes the small numbers of shareholders protection against the official seizure by a government of the private property by controlling shareholders. In addition, we will adopt the idea of (Djankov, 2008) as our fourth proxy, the anti-self-dealing index (AS) which captures outside investors protection against self-dealing by managing shareholders. To create two country-level proxies, we will further follow the prior literature to ensure the quality of accounting information. According to LaPorta et al. (1998) incorporate financial reporting, the first is the accounting quality index (ACCT) based on the omission of reporting of 90 items.

The asset growth rate (AG) is the main variable of interest followed by Cooper et al. (2008). For statistical inference, using the White (1980) heteroskedasticity-robust standard errors, for the cross-sectional regressions the research computed $t$-statistics. We note that to perform country-level analysis many researchers adopted this approach; see e.g., LaPorta et al. (1997) Demirgüç-Kunt and Maksimovic (1999), Karolyi et al. (1999), Morck, et al. (2000), Durnev et al. (2003), and Djankov et al. (2007).

To evaluate the robustness of the effect of asset growth we use the Fama-McBeth regressions. The $p$-value was attained from the pairwise correlation calculated by STATA. Using multiple regressions, we calculate SLOPE2. In addition, in parenthesis, t-statistics are reported which are computed using robust standard errors. Statistical significance $10 \%, 5 \%$, and $1 \%$ levels pointed to $*, * *$ and $* * *$, respectively. Most of the calculations are done by STATA.

\section{Findings}

It is found that the cross-firm variation in the rate of asset growth is exactly almost twice exclude the United States (39.92\%) than in U.S (74.28\%). Previously Chen et al. (2011) and Watanabe et al. (2013) respectively 9 Asian markets and 54 global markets have been shown the greater percentage of asset growth rates relative to the United States.

\subsection{Asset Growth Effect within Countries}

The magnitude of the effect of asset growth in every 12 countries containing 15 stocks. Some countries like Australia, Japan, China, Philippines, Brazil, Israel, and Canada have higher AGSPREAD than the United States. Further, the result shows that out of 12 countries, 9 and 10 have positive values of equal weighted SPREAD and SLOPE respectively. Thus, we can see the negative connection between asset growth and stock return. The value weighted SPREAD and SLOPE show out of 12 countries, 9 and 8 have positive values of equal weighted SPREAD and SLOPE respectively. Thus, we also can see the negative connection between asset growth and stock return. There is also the existence of a large distribution in the magnitude of the value weighted AG effect. Under country neutral or global pooling, without or with considering U.S the result for SLOPE is always positive. Overall, results indicate the existence of the effect of asset growth in the global market.

\subsection{Asset Robustness and Variations}

The research assessed the regression for the United States by both equal and value weighting followed by 
McLean et al. (2009) and compute regressions by both scale and equal weighting for the country pooled sample. Each farm-return observation is assigned by the scale-weighting regressions that weigh that equivalent to the market value of the company's dividend by the average market value. Since within-country value-weight is equalled the scale-weight, both regressions results show the variations of the AG effect between large and small firms within each country.

7.2.1 Robustness of the Effect of Asset Growth: Controlling for Additional Firm Characteristics and Alternative Horizons and Weighting

The table reports the result of the robustness of the effect of asset growth examined by the Fama-MacBeth (1973) regressions. Excluding the United States, Panel $\mathrm{X}$ shows results for stocks pooled, and the results for U.S. stocks report in Panel Y. For time-series autocorrelation the $t$ - statistics are adjusted and reported in parenthesis. Statistical significance $10 \%, 5 \%$, and $1 \%$ levels pointed to $* * *$ and $* * *$, respectively.

Panel X. all countries excluding the United States

\begin{tabular}{|l|l|l|l|l|l|l|}
\hline \multirow{2}{*}{ Horizon } & \multicolumn{2}{|l|}{ Year 1 } & \multicolumn{2}{l|}{ Year 2 } & \multicolumn{2}{l|}{ Year 3 } \\
\cline { 2 - 7 } Weighting & Equal & Scaled & Equal & Scaled & Equal & Scaled \\
\hline AG & $-0.067^{*}$ & 0.685 & $0.129^{*}$ & 0.177 & $-0.030^{*}$ & 0.134 \\
& $(0.194)$ & $(5.674)$ & $(0.637)$ & $(-0.213)$ & $(0.054)$ & $(-0.172)$ \\
\hline ME & $0.199^{* * *}$ & -0.134 & -0.269 & -0.484 & -0.496 & -0.268 \\
& $(0.133)$ & $(0.263)$ & $(0.219)$ & $(0.816)$ & $(0.893)$ & $(-0.450)$ \\
\hline BM & $0.125^{*}$ & $0.718^{*}$ & $0.039^{*}$ & $0.612^{*}$ & $0.0718^{*}$ & $0.519^{* * *}$ \\
& $(0.126)$ & $(0.131)$ & $(0.318)$ & $(0.417)$ & $(0.131)$ & $(0.115)$ \\
\hline MOM & $0.048^{*}$ & $-0.254^{* * *}$ & $1.020^{*}$ & $-0.254^{* * *}$ & $0.629^{*}$ & $-1.189^{*}$ \\
& $(0.104)$ & $(1.125)$ & $(0.404)$ & $(1.152)$ & $(0.101)$ & $(0.576)$ \\
\hline Intercept & $0.362^{*}$ & $0.209^{* * *}$ & $0.354^{*}$ & $0.184^{*}$ & $0.184^{*}$ & $0.118^{*}$ \\
& $(3.645)$ & $(3.635)$ & $(1.635)$ & $(2.282)$ & $(2.227)$ & $(1.292)$ \\
\hline R2 & 0.146 & 0.018 & 0.009 & 0.026 & 0.002 & 0.027 \\
\hline
\end{tabular}

Panel Y. U.S.

\begin{tabular}{|l|l|r|l|l|l|l|}
\hline \multirow{2}{*}{ Horizon } & \multicolumn{2}{|l|}{ Year 1 } & \multicolumn{2}{l|}{ Year 2 } & \multicolumn{2}{l|}{ Year 3 } \\
\cline { 2 - 7 } Weighting & Equal & Scaled & Equal & Scaled & Equal & Scaled \\
\hline AG & $-1.071^{* * *}$ & 0.119 & $0.204^{*}$ & -0.003 & 0.116 & -0.278 \\
& $(0.998)$ & $(1.701)$ & $(0.135)$ & $(1.749)$ & $(0.385)$ & $(0.277)$ \\
\hline ME & -0.306 & $-0.441^{*}$ & 0.434 & $-0.387^{*}$ & -0.583 & $-0.013^{*}$ \\
& $(0.837)$ & $(0.061)$ & $(0.829)$ & $(0.542)$ & $(0.844)$ & 0.055 \\
\hline BM & $-1.035^{* *}$ & -3.244 & $-0.704^{* * *}$ & -2.574 & $-0.663^{* *}$ & -2.574 \\
& $(1.101)$ & $(6.081)$ & $(1.197)$ & $(6.010)$ & $(1.220)$ & $(6.101)$ \\
\hline MOM & $-0.004^{*}$ & $-0.003^{*}$ & $0.002^{*}$ & $-0.002^{*}$ & $-0.002^{*}$ & $-0.002^{*}$ \\
& $(0.576)$ & $(0.020)$ & $(0.1 .10)$ & $(0.023)$ & $(0.107)^{*}$ & $(0.023)$ \\
\hline Intercept & $0.180^{* * *}$ & $0.176^{* *}$ & $0.264^{* * *}$ & $0.119^{*}$ & $0.178^{* * *}$ & $0.354^{* *}$ \\
& $(3.055)$ & $(2.655)$ & $(3.666)$ & $(1.876)$ & $(3.606)$ & $(2.645)$ \\
\hline R2 & 0.001 & 0.388 & 0.002 & 0.037 & 0.003 & 0.004 \\
\hline
\end{tabular}

Table 3 in Panel $\mathrm{X}$ depicts that the effects of the asset growth excluding the United States are robust to the control by ME, BM, and MOM. The asset growth equal weighted coefficients are significant negative for three consecutive years, though with the time horizon its turn less statically significant. The scaled-weighted coefficient is notable for year one. Panel Y reported the regression result for the United States to depict that the coefficients of AG are significant for the first two years but insignificant in the last year under equal weighting. Further reveals by comparing the regression coefficients of Panel $\mathrm{X}$ and $\mathrm{B}$, after controlling for the value, size, and momentum effects, in the term of the AG effect magnitude the international markets does not dominate by the United States market. For example, the equal weighted effect AG coefficient is -0.067 for the first year returns for the United States. versus outside the international market, the United States is 1.071. Overall, in international markets, these results point towards a robust negative asset growth effect on future stock returns.

\subsubsection{The Effects of Asset Growth: Controlling for Firm Profitability}

The annual returns percentage on two-way arranged portfolios reports in this table, which reports the effects of asset growth after controlling for firm profitability. The table depicts the effect of asset growth that continues to 
exist after controlling for firm profitability. From the table, equal weighted portfolios, subtracting the top from bottom AG quintiles of the time-series averages of spread and return we find $5.31 \%, 8.22 \%, 5.99 \%$, and $7.90 \%$ across the five ROE quintiles.

Panel X. Equal weighted portfolios

\begin{tabular}{|l|l|l|l|l|}
\hline & $\begin{array}{l}\text { Low } \\
\text { ROE }\end{array}$ & $\mathbf{2}$ & $\mathbf{3}$ & $\begin{array}{l}\text { High } \\
\text { ROE }\end{array}$ \\
\hline Low AG & 22.98 & 21.89 & 11.55 & 11.92 \\
\hline & 12.09 & 12.56 & 16.87 & 19.82 \\
\hline & 17.67 & 17.07 & 17.00 & 19.52 \\
\hline High AG & 20.91 & 13.67 & 17.89 & 13.93 \\
\hline $\begin{array}{l}\text { Low-High } \\
\text { t-Stat }\end{array}$ & $5.31 *$ & 8.22 & 5.99 & $7.90 * *$ \\
$(3.43)$ & $(2.13)$ & $(1.98)$ & $(2.25)$ \\
\hline
\end{tabular}

Panel Y. value weighted portfolios

\begin{tabular}{|l|l|l|l|l|}
\hline & $\begin{array}{l}\text { Low } \\
\text { ROE }\end{array}$ & $\mathbf{2}$ & $\mathbf{3}$ & $\begin{array}{l}\text { High } \\
\text { ROE }\end{array}$ \\
\hline Low AG & 12.54 & 21.72 & 17.81 & 17.19 \\
\hline & 16.21 & 15.83 & 14.91 & 18.99 \\
\hline & 15.99 & 19.07 & 18.23 & 17.82 \\
\hline High AG & 20.29 & 13.63 & 17.54 & 20.92 \\
\hline $\begin{array}{l}\text { Low-High } \\
\text { t-Stat }\end{array}$ & $\begin{array}{l}7.71 * * \\
(2.41)\end{array}$ & $\begin{array}{l}8.09 \\
(4.83)\end{array}$ & $\begin{array}{l}3.32 * * * \\
(1.54)\end{array}$ & $\begin{array}{l}7.19 * * \\
(5.73)\end{array}$ \\
\hline
\end{tabular}

The third and fourth quintiles are not statically significant but relatively close to it. We can see similar results for value weighted portfolios. The return spreads between the top and bottom AG across the four ROE are 7.71\%, $8.09 \%, 3.32 \%$, and $7.19 \%$, except for the second ROE quintiles all significantly positive. The $q$ theory prediction on the returns on investments is in line with the results.

\subsubsection{Correlation of Country Characteristics}

The country characteristic proxies are investor protection, market efficiency, accounting quality and limits-to-arbitrage.

\begin{tabular}{|c|c|c|c|c|c|c|c|}
\hline & $r 2$ & ferc & dev & short & $\mathrm{cr}$ & $\mathrm{ad}$ & as \\
\hline r2 & 1.0000 & & & & & & \\
\hline \multirow[t]{2}{*}{ ferc } & 0.2610 & 1.0000 & & & & & \\
\hline & 0.4383 & & & & & & \\
\hline \multirow[t]{2}{*}{ dev } & -0.2609 & $0.7507 *$ & 1.0000 & & & & \\
\hline & 0.4128 & 0.0078 & & & & & \\
\hline \multirow[t]{2}{*}{ short } & 0.1612 & 0.2357 & 0.3568 & 1.0000 & & & \\
\hline & 0.6166 & 0.4854 & 0.2550 & & & & \\
\hline \multirow[t]{2}{*}{$\mathrm{Cr}$} & 0.0667 & 0.4451 & 0.5111 & 0.0249 & 1.0000 & & \\
\hline & 0.8456 & 0.1701 & 0.1081 & 0.9421 & & & \\
\hline \multirow[t]{2}{*}{$\mathrm{ad}$} & 0.1961 & 0.1405 & 0.2688 & $0.7918 *$ & 0.4501 & 1.0000 & \\
\hline & 0.5413 & 0.6804 & 0.3982 & 0.0021 & 0.1648 & & \\
\hline \multirow[t]{2}{*}{ as } & -0.0775 & 0.4082 & 0.4849 & -0.1459 & $0.8398 *$ & 0.1599 & 1.0000 \\
\hline & 0.8109 & 0.2127 & 0.1101 & 0.6510 & 0.0012 & 0.6196 & \\
\hline \multirow[t]{3}{*}{ acct } & -0.0768 & 0.4448 & 0.5298 & . & $0.7389 *$ & 0.2452 & $0.8572 *$ \\
\hline & 0.8225 & 0.1977 & 0.0937 & . & 0.0146 & 0.4674 & 0.0007 \\
\hline & $\operatorname{acct}$ & & & & & & \\
\hline $\operatorname{acct}$ & 1.0000 & & & & & & \\
\hline
\end{tabular}


The fact, that the limit-to-arbitrage proxies are positively correlated with the market efficiency but negatively correlated with the investor protection. From the optimal investment explanation, it is found that higher market efficiency leads to a stronger negative effect on the rate of asset growth and stock returns. On the other hand, according to the explanations of mispricing, some factors such as poorer accounting quality, severer limits to arbitrage, and weaker corporate governance contribute to making stronger the effect of asset growth. Under mispricing arguments, these contributing factors and degree of market efficiency are inversely related which is strongly noticeable. In conclusion, the effect is more likely due to the company's optimal investment behaviour

We find in the empirical analysis that the time-invariant variables of the country characteristics contain the AG effect explanatory powers but the country characteristics time-varying part do not have power. Alternatively, stock markets connection between the AG effect and the country characteristics is in the form of the between effect. That is why, to capture the between-effect, the empirical results structure are reported based on the cross-sectional regression

\subsubsection{Information Efficiency Analysis}

The results of the cross country regressions report in this table examine the connection between asset growth and market efficiency. The dependent variables SPREAD and SLOPE is the within-country time-series averages of the asset growth effect measures. The regression results for Panel X and Panel Y, the dependable variable SPREAD and SLOPE respectively used for the equal weighted or value weighted SPREAD and SLOPE. Market efficiency proxies are explanatory variables, including stock return synchronicity R2, the developed-market indicator DEV, and future earnings response FERC. In parenthesis, t-statistics are reported which are calculated using robust standard errors. Statistical significance $10 \%, 5 \%$, and $1 \%$ levels pointed to $*, * *$ and ***, respectively.

Panel X. Dependent variable, SPREAD

\begin{tabular}{|c|c|c|c|c|c|c|c|c|}
\hline \multicolumn{5}{|c|}{ Equal weighted SPREAD } & \multicolumn{4}{|c|}{ Value weighted SPREAD } \\
\hline Model & 1 & 2 & 3 & 4 & 1 & 2 & 3 & 4 \\
\hline $\mathrm{r} 2$ & $\begin{array}{l}-0.313^{*} \\
(-2.023)\end{array}$ & & & & $\begin{array}{l}-0.568^{*} \\
(-1.088)\end{array}$ & & & \\
\hline Ferc & & $\begin{array}{l}0.041 * * \\
(2.211)\end{array}$ & & & & $\begin{array}{l}0.098^{*} \\
(2.161)\end{array}$ & & \\
\hline Dev & & & $\begin{array}{l}0.0081 \\
(2.007)\end{array}$ & & & & $\begin{array}{l}0.196^{* *} \\
(4.211)\end{array}$ & \\
\hline Intercept & $\begin{array}{l}0.042 \\
(3.984)\end{array}$ & $\begin{array}{l}0.037^{*} \\
1.938\end{array}$ & $\begin{array}{l}0.033 * * \\
(0.029)\end{array}$ & $\begin{array}{l}0.094 * * * \\
(2.020)\end{array}$ & $\begin{array}{l}0.067 \\
(3.556)\end{array}$ & $\begin{array}{l}-0.127 \\
(-2.978)\end{array}$ & $\begin{array}{l}0.098^{*} \\
(1.051)\end{array}$ & $\begin{array}{c}-0.565^{*} \\
(-4.090)\end{array}$ \\
\hline
\end{tabular}

Panel Y. Dependent variable, SLOPE

\begin{tabular}{|l|l|l|l|l|l|l|l|l|}
\hline \multicolumn{5}{|c|}{ Equal weighted SLOPE } & \multicolumn{3}{c|}{ Value weighted SLOPE } \\
\hline Model & 1 & 2 & 3 & 4 & 1 & 2 & 3 & 4 \\
\hline r2 & $-1.456^{*}$ & & & & $\begin{array}{l}-2.509^{*} \\
(-1.088)\end{array}$ & & & \\
& $(-2.023)$ & & & & & $\begin{array}{l}0.098^{*} \\
(2.161)\end{array}$ & & \\
\hline Ferc & & $\begin{array}{l}0.675^{* *} \\
(2.211)\end{array}$ & & & & & & $0.196^{* *}$ \\
& & & 0.871 & & & & \\
\hline Dev & & & $(2.007)$ & & & & & \\
& & & & & & & & \\
\hline Intercept & 0.092 & $0.987^{*}$ & $-0.033^{*}$ & $-0.060^{* *}$ & 0.009 & 0.127 & $-0.458^{*}$ & $0.095^{*}$ \\
& $(0.454)$ & 1.938 & $(-0.877)$ & $(-1.009)$ & $0.096)$ & $(1.009)$ & $(-0.250)$ & $(0.560)$ \\
\hline
\end{tabular}

To get $\mathrm{H}_{1}$, the empirical outcome regarding the cross-country connection between the AG effect and the market efficiency, the researcher used cross-sectional regressions between country effects. The table reports that with low R2 and higher FERC both the value and equal weight are considerably higher. DEV indicates developed markets. R2, FERC, and DEV together were used in multiple regressions as an explanatory variable. The coefficient for FERC becomes insignificant, probably due to strong correlations among R2 and DEV.

Panel Y reports a stronger AG effect with greater information efficiency. In this analysis, the mispricing-based 
hypothesis is inconsistent but steady with the forecast of the hypothesis of the optimal investment. From the findings, it is seen that the $\mathrm{H}_{1}$ is accepted.

\subsubsection{Cross-country Analysis of the Asset Growth Effect and Market Efficiency}

Based on multiple regressions we attain both value and equal weighted dependent variable SPREAD2 and SLOPE2 measures which are the similar construction of SPREAD and SLOPE. The results of the univariate regression reported that the dependent variables both value weighted and equal weighted are considerably higher with lower R2, DEV and higher FERC indicate a developed market. All three regressors are jointly included in multiple regressions, FERC, R2 and DEV maintain to show important impact on AG effect magnitude for each country. Our results, therefore, lend advance support to our prior conclusion that stronger investment leads to greater market efficiency, consistent with the optimal investment hypothesis.

\subsubsection{Limits to Arbitrage Analysis}

The regressions results of the cross country report connection between asset growth effect and limits to arbitrage. $\mathrm{H} 2$ on the connection between the AG effect and the limits to arbitrage. As we state, $\mathrm{H} 2$, in countries will have stronger the AG effect with lower SHORT- the short-selling restrictions is in effect. Therefore, the cross-country regressions should yield a negative slope on SHORT and the result is consistent with H2. Therefore, $\mathrm{H}_{\mathrm{o}}$ rejected.

In countries, there is a stronger $\mathrm{AG}$ effect with greater idiosyncratic volatilities consistent with the limits-to-arbitrage argument prediction. However, SHORT is the limits-to-arbitrage proxy that does not have noteworthy explanatory power on the country level AG effect. The coefficient on the limits-to-arbitrage proxy is still insignificant under multiple regressions. In contrast, none of the limits-to-arbitrage variables' coefficients is significant.

Based on current studies on U.S. individual stock data, Lam and Wei (2011), Lipson et al. (2011) and Li and Zhang (2010) studies identify that the negative effect of asset growth rates is stronger on consequent stock return for a company' with severer limits-to-arbitrage. On the other hand, using international data in our analysis finds the arbitrage costs role is reasonably weak in describing the effect of asset growth at the country level.

\subsubsection{Accounting Quality and Investor Protection Analysis}

The measure of the accounting quality and investor protection are the explanatory variables including the accounting standard index ACCT, the anti-self-dealing index AS, the revised anti-director index AD, and the credit right index CR. Under the final hypothesis (H3), the coefficient for ACCT, AD, CR, AS are forecasted to be negative. It shows that calculated most of the accounting quality and protection of investor proxies are insignificant with few exceptions. The first exception in the multiple regressions AS bears a significant negative SLOPE when the dependant variable is the equal weighted SPREAD (available in Panel X ), value weighted SLOPE / equal weighted SLOPE (available in Panel Y). The reports show a stronger negative relationship between investment and return in those countries in which protection of investors is weaker measured by AS. Mispricing-based hypothesis is consistent with this significant evidence. These reports are consistent with the prediction of $\mathrm{H} 3$ but the last evidence that stands against $\mathrm{H} 3$ is the value weighted SPREAD and SLOPE provide strong positive effects of ACCT. These reports indicate that, weakening of the quality of accounting decreases the AG effect magnitude which contradicts the mispricing-based arguments.

The research found that the accounting quality and investor protection with the AG effect have a positive relationship as pointed by the significant results in the above table probably described by the effect of optimal investment. With lessen room for earnings manipulation; insiders' incentives support more with outsiders', managers' incentives support more with shareholders and better protection. Thus, value-enhancing investments are probably to undertake by firms, leading to a clearer effect of investment based on q theory. As it is conditional this is subsequent order effect on the informationally efficient financial markets being in the first place. Our report finds somewhat conflicting and weak evidence for $\mathrm{H} 3$ regarding the accounting quality and protection of investor effect on the relation between investment and return. Part of the result accepts $\mathrm{H}_{3}$ and the rest of the part support $\mathrm{H}_{0}$.

\subsubsection{Horse-race among Competing Statements}

The research so far examined how country each characteristics group separately influences the magnitude of the effect of asset growth. The correlation among the country characteristics may confuse our conclusion as a natural concern. In cross-country analysis, the correlation patterns reported that the more efficient markets tend to have higher accounting quality, better investor protection, fewer limits to arbitrage. The measures of accounting quality and investor protection seem to correlate with the limits to arbitrage, although the guidelines of their correlations are diverse. In cross-country analysis, we have argued that the particular patterns of correlation 
scrutinised between the remaining country characteristics and the market efficiency proxies enhanced our aptitude to distinguish between the mispricing and the optimal investment hypothesis. Whereas opposite prediction constructs by the two hypotheses as to how asset growth should affect by the country characteristics. The minor concern of our study may be the confounding issue. Nevertheless, combined effects of the country characteristics variable given their extensive correlations is desirable to investigate. The combined investigations also permit us to spot the chances that one effect (for example, the mispricing based effect) when we manage for others that emerges strongly (for example, optimal investment effect). To investigates the comparative significance of the mispricing and the optimal investment effect, we carry on rely on multiple regression cross-country analysis. In regression analysis, the within country mean of SPREAD / SLOPE is the dependent variable as uses earlier. However, all the country characteristics cannot be included in a single regression.

\subsubsection{Cross Country Analysis of Mispricing-Based Effect vs. Optimal Based Effect}

For most of the regressions, the prediction of the optimal investment explanation conforms to the signs of the coefficients on the efficiency proxies' information. (i.e., positive slopes on DEV and FERC and negative slope on R2). The 42 out of 54, at least at the $10 \%$ level coefficients are significant. Furthermore, efficiency measures show that the effects are insignificant in the remaining 8 cases. In addition, mispricing-based variables show counterintuitive or insignificant effects. Jointly, we come across no evidence that the firms' optimal investment behaviour dominates by the mispricing based factors in driving asset growth effect.

Now consider the role of limits-to-arbitrage, it can be seen that the coefficients on SHORT are mainly insignificant. When included together with FERC or R2 then only three 3 exceptions are the notably positive effect on SPREAD (Panel X and B respectively), and when added alongside FERC, SHORT has the significantly negative effect on SPREAD (Panel Y). In countries, the result shows a greater average short-selling restriction with stronger AG effect and idiosyncratic volatility, steady with the mispricing-based perception. It can be noted that, in above all circumstances where the proxies of limits-to-arbitrage have considerable slopes, R2 and FERC, the market efficiency measures also contain significant coefficients. We conclude the limits to arbitrage role affecting the AG affect the magnitude is comparably weak and the optimal investment effect does not eliminate the significance by it.

Finally, we also see that the slopes on the accounting quality and protection of investor proxies are also insignificant. In all the cases, the regression coefficients on ACCT are positive, signifying that the AG effect strengthens as the accounting quality and protection of investors improve. This finding may be related to the next level of optimal investment effect but contradict the mispricing based explanation. Specifically, as the accounting quality and investor protection get better, making the q theory-based investment effect clearer, firms probably undertake value-enhancing investments. Overall, the outcomes of the multiple regressions on cross-country suggest that the finding for the mispricing based effect is not strong, while tends to be much more prevailing for the optimal investment effect.

\section{Results}

The research identified that there is a stronger AG effect with greater information efficiency. The mispricing-based hypothesis is inconsistent with the mispricing-based hypothesis but steady with the forecast of the hypothesis of the optimal investment. In addition, the regressions of cross-country should yield a negative slope on the short-selling restrictions is in effect to be consistent with the second hypothesis. Moreover, the research showed a stronger negative relationship between investment and return in those countries in which protection of investors is weaker cross-examined by the anti-self-dealing index. The mispricing-based hypothesis was consistent with this significant evidence. This research prediction is consistent with the final hypothesis but the last evidence that stands against the hypothesis is the value weighted SPREAD and SLOPE provide strong positive effects of accounting quality index. This research suggested that weakening of the accounting quality decreases the AG effect magnitude which contradicts the mispricing-based arguments.

\section{Contribution}

The prior literature shows a negative connection between firms' financing activities and investment with future stock returns. Most importantly, Cooper et al. (2008) demonstrate that U.S firms with lower rates of asset growth are likely to have higher consequent stock returns. Nevertheless, the research tried to verify a common dispute on whether such a practical pattern is the outcome of market mispricing or can be seen as an effect of optimal corporate investment.

The research showed that the effect of asset growth exists in the international markets besides the United States 
Additionally, this research is useful evidence that lets us examine the mispricing based statement of the effect of asset growth in comparison with the optimal investment explanation. There are large differences in a variety of measures of market efficiency, accounting quality, protection of the investor and the asset growth effect across the 12 equity markets we examine. The competing hypotheses anticipate that the magnitudes of the asset growth effect are related to these country characteristics in diverse ways. We can see that the strongest power possessing by the country characteristics to describe the magnitude of the effect of asset growth is connected to the market efficiency- informationally efficient markets have a stronger asset growth effect. Alternatively, country characteristics representing accounting quality, investor protection, and limits to arbitrage have inadequate power to describe the difference of the effect of asset growth across international markets.

\section{Recommendations}

The study will join the expanding literature. For example, McLean et al (2009) and Hou (2011) seek international evidence for different types of stock returns expectedness initially recognized in the United States. The incremental involvement of this paper will take advantage of across countries in the AG effect and will give a fresh set of perceptions. The result of this research paper will be connected to a new characteristic that is expected to be significant to practitioners. Similarly, the outcome will help in better understanding the determinants of the return. In understanding the determinants of returns and investment implications the academics will be interested. Another particular interest would be short to long portfolio performance containing low and high growth stocks respectively.

\section{Conclusion}

The prior literature shows a negative connection between firms' financing activities and investment with future stock returns. Most importantly, Cooper et al. (2008) demonstrate that U.S firms with lower rates of asset growth are likely to have higher consequent stock returns. Nevertheless, the research tried to verify a common dispute on whether such a practical pattern is the outcome of market mispricing or can be seen as an effect of optimal corporate investment. The research found that the effect of asset growth exists in the international markets besides the United States. Additionally, the research successfully presented useful evidence that lets us examine the mispricing based statement of the effect of asset growth in comparison with the optimal investment explanation. There are large differences in a variety of measures of market efficiency, accounting quality, protection of the investor and the asset growth effect across the 12 equity markets we examine. The competing hypotheses anticipate that the magnitudes of the asset growth effect are related to these country characteristics in diverse ways. We can see that the strongest power possessing by the country characteristics to describe the magnitude of the effect of asset growth is connected to the market efficiency- informationally efficient markets have a stronger asset growth effect. Alternatively, country characteristics representing accounting quality, investor protection, and limits to arbitrage have inadequate power to describe the variation of the effect of asset growth across international markets.

\section{References}

Baker, M., \& Wurgler, J. (2002). Market Timing and Capital Structure. Journal of Finance, 57(1), 1-32. https://doi.org/10.1111/1540-6261.00414

Chen, L., Novy-Marx, R., \& Zhang, L. (2011). An alternative three-factor model. Unpublished working paper. Cheung Kong Graduate School of Business, University of Rochester, Ohio State University. https://doi.org/10.2139/ssrn.1418117

Collins, D. W., Kothari, S., Shanken, J., \& Sloan, R. J. (1994). Lack of timeliness and noise as explanations for the low contemporaneous return-earnings association. Journal of Accounting and Economics, 18(3), 289-324. https://doi.org/10.1016/0165-4101(94)90024-8

Cooper, M., Gulen, H., \& Schill, M. (2008). Asset Growth and the Cross-section of Stock Returns. Journal of Finance, 63(4), 1609-1651. https://doi.org/10.1111/j.1540-6261.2008.01370.x

Cochrane, J. H. (1996). A cross-sectional test of an investment-based asset pricing model. Journal of Political Economy, 104(3), 572-621. https://doi.org/10.1086/262034

Cochran, J. H. (2011). Production-based asset pricing and the link between stock returns and growth effect. Journal of Financial and Quantitative Analysis, 46(1), 1651-1682. https://doi.org/10.1017/S0022109011000561

Demirgüç-Kunt, A., \& Maksimovic, V. (1999). Institutions, financial markets, and firm debt maturity, Journal of Financial Economics, 54(3), 295-336. https://doi.org/10.1016/S0304-405X(99)00039-2 
Djankov, S., McLiesh, C., \& Shleifer, A. (2007). Private credit in 129 countries'. Journal of Financial Economics, 23, 299-323. https://doi.org/10.1016/j.jfineco.2006.03.004

Djankov, S., LaPorta, R., Lopez-de-Silanes, F., \& Shleifer, A. (2008). The law and economics of self-dealing. Journal of Financial Economics, 88(3), 430-465. https://doi.org/10.1016/j.jfineco.2007.02.007

Durnev, A., Morck, R., Yeung, B., \& Zarowin, P. (2003). Does greater firm-specific return variation mean more or less informed stock pricing? Journal of Accounting Research, 41(5), 797-836. https://doi.org/10.1046/j.1475-679X.2003.00124.x

Fama, E. F., \& MacBeth, J. D. (1973). Risk, Return, and Equilibrium: Empirical Tests. Journal of Political Economy, 81(3), 607-636. https://doi.org/10.1086/260061

Hou, K., Karolyi, G. A., \& Kho, B. C. (2011). What factors drive global stock returns? Review of Financial Studies, 2, 173-197. https://doi.org/10.2139/ssrn.908345

Karolyi, G. A., Lee, K. H., \& Van Dijk, M. A (1999). Institutions, financial markets, and firm debt maturity. Journal of Financial Economics, 54, 295-336. https://doi.org/10.1016/S0304-405X(99)00039-2

Lakonishok, J., Shleifer, A., \& Vishny, R. W. (1994). Contrarian investment extrapolation and risk. Journal of Finance, 49(5), 1541-1578. https://doi.org/10.1111/j.1540-6261.1994.tb04772.x

Lam, F. E. C., \& Wei, K. J. (2011). Limits-to-arbitrage, investment frictions, and the asset growth anomaly. Journal of Financial Economics, 26(1), 3-43. https://doi.org/10.1016/j.jfineco.2011.03.024

LaPorta, R., Lopez-de-Silanes, F., Shleifer, A., \& Vishney, R. W. (1997). Legal determinants of external finance. Journal of Finance, 52(3), 1131-1150. https://doi.org/10.1111/j.1540-6261.1997.tb02727.x

LaPorta, R., Lopez-de-Silanes, F., Shleifer, A., \& Vishney, R. W. (1998). Law and finance. Journal of Political Economy, 106(6), 1113-1155. https://doi.org/10.1086/250042

Li, L. X. N., Livdan, D., \& Zhang, L. (2009). Anomalies. Review of Financial Studies, 22(11), 4301-4333. https://doi.org/10.1093/rfs/hhp023

Li, D., \& Zhang, L. (2010). Does q-theory with investment frictions explain anomalies in the cross-section of returns? Journal of Financial Economics, 98, 297-314. https://doi.org/10.1016/j.jfineco.2010.06.001

Liu (2009). Investment-based expected stock returns. Journal of Political Economy, 117(6), 1105-1139. https://doi.org/10.1086/649760

Lyandres, E., Sun, L., \& Zhang, L. (2008). The new issue puzzle: testing the investment based explanation. Review of Financial Studies, 21(6), 2825-2855. https://doi.org/10.1093/rfs/hhm058

Morck, R., Yeung, B., \& Yu, W. (2000). The information content of stock markets: Why do emerging markets have synchronous stock price movements? Journal of Financial Economics, 58(1-2), 215-260. https://doi.org/10.1016/S0304-405X(00)00071-4

McLean, R. D., Pontiff, J., \& Watanaebe, A. (2009). Share issuance and cross-sectional returns: international evidence. Journal of Financial Economics, 94(1), 1-17. https://doi.org/10.1016/j.jfineco.2008.09.009

Teoh, S. H., Welch, I., \& Wong, T. J. ( 1998a). Earnings management and the long-run market performance of initial public offerings. Journal of Finance, 53(6), 1953-1973. https://doi.org/10.1111/0022-1082.00079

Teoh, S. H., Welch, I., \& Wong, T. J. (1998b) 'Earnings management and the underperformance of seasoned equity offerings. Journal of Financial Economics, 50(1), 63-99.

Titman, S. (2004). Capital investment and stock returns. Journal of Financial and Quantitative Analysis, 39(4), 677-700. https://doi.org/10.1017/S0022109000003173

Titman, S., Wei, K. C. J., \& Xie, F. (2011). Access to equity markets, corporate investments and stock returns: international evidence. Unpublished working paper. University of Texas at Austin, Hong Kong University of Science and Technology, University of Texas at El Paso. https://doi.org/10.2139/ssrn.1571648

Tobin (1969). A General Equilibrium Approach to Monetary Theory. Journal of Money, Credit and Banking, I(1), 15-19. https://doi.org/10.2307/1991374

Watanabe, S., Wei, K. C. J., \& Xie, F. (2013). The Asset Growth Effect: Insights from international equity markets. Journal of Financial Economics, 108(2), 529-563. https://doi.org/10.1016/j.jfineco.2012.12.002

White, H. (1980). A heteroskedasticity-consistent covariance matrix estimator and a direct test for heteroskedasticity. Econometrica, 48(4), 817-838. https://doi.org/10.2307/1912934 
Wu, G., Zhang, F., \& Zhang, L. (2010). The q-theory approach to understanding the accrual anomaly. Journal of Accounting Research, 48(1), 177-223. https://doi.org/10.1111/j.1475-679X.2009.00353.x

Yoshikawa, H. (1980). On the 'q' Theory of Investment. American Economic Review, 70(4), 739-743.

\section{Copyrights}

Copyright for this article is retained by the author(s), with first publication rights granted to the journal.

This is an open-access article distributed under the terms and conditions of the Creative Commons Attribution license (http://creativecommons.org/licenses/by/4.0/). 